\title{
TEKANAN FLASHING OPTIMAL PADA PEMBANGKIT LISTRIK TENAGA PANAS BUMI SISTEM DOUBLE-FLASH
}

\author{
Rafif Tri Adi Baihaqii ${ }^{\text {a) Hensen P. K. Sinulingga }}{ }^{\text {b) }}$, \\ Muhamad Ridwan Hamdanic) \\ Program Studi Fisika, \\ Fakultas Matematika dan Ilmu Pengetahuan Alam, Universitas Padjadjaran \\ Jl. Raya Bandung-Sumedang Km 21, Jatinangor 45363
}

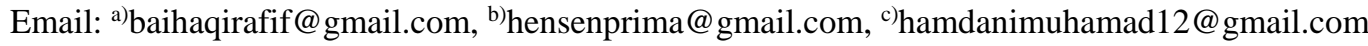

\begin{abstract}
Abstrak
Sumber panas bumi di Indonesia merupakan sumber dengan sistem hydrothermal yang didominasi oleh jenis dominasi air, dengan karakteristik sekitar $20 \%$ uap dan $80 \%$ air. Jenis pembangkit di Indonesia yang digunakan saat ini untuk memanfaatkan sumber dominasi air adalah sistem single-flash. Brine hasil flashing dari sistem ini masih memiliki temperatur yang tinggi sehingga masih bisa digunakan sebagai sumber energi baru, yaitu menggunakan sistem double-flash. Penelitian ini membuat model pembangkit listrik tenaga panas bumi sistem doubleflash untuk memanfaatkan brine hasil flashing sehingga diperoleh daya yang lebih besar. Tujuan dilakukannya penelitian ini adalah untuk mengetahui tekanan flashing optimal pada pembangkit listrik tenaga panas bumi sistem double-flash. Pada penelitian ini variasi perubahan tekanan yang digunakan sebesar 4 bar, 5 bar, 6 bar, 7 bar, 8 bar, dan 9 bar. Berdasarkan hasil penelitian dapat diketahui bahwa daya turbin maksimal dapat dihasilkan ketika perubahan tekanan $(\Delta \mathrm{P})$ flashing berada pada 7 bar yang menghasilkan daya sebesar 9,575 MW dengan efisiensi $82,68 \%$.
\end{abstract}

Kata-kata kunci: brine, flashing, single-flash, double-flash, perubahan tekanan.

\begin{abstract}
Geothermal resources in Indonesia are hydrothermal system dominated by water, with characteristic about 20\% steam and $80 \%$ water. The type of power plant in Indonesia currently used to utilize the source of water dominance is a single-flash system. Brine results from this flashing system still have a high temperature so it can still be used as a new energy source, which uses a double-flash system. This research makes a model of geothermal power plant double-flash system to utilize brine results from flashing so that obtained bigger power. The purpose of this research is to know the optimal flashing pressure in a double-flash geothermal power plant. In this research, the variation of pressure change used was 4 bar, 5 bar, 6 bar, 7 bar, 8 bar, and 9 bar. Based on the research results, it can be seen that maximum turbine power can be generated when the pressure change $(\Delta \mathrm{P})$ of flashing is at 7 bar which generate power 9,575 MW with efficiency $82,68 \%$.
\end{abstract}

Keywords: brine, flashing, single-flash, double-flash, pressure change. 


\section{PENDAHULUAN}

Sistem panas bumi merupakan salah satu sistem yang terjadi dalam proses geologi yang berjalan dalam orde ratusan bahkan jutaan tahun yang dewasa ini membawa manfaat bagi manusia baik dimanfaatkan secara langsung maupun tidak lansung. Pemanfaatan secara langsung umumnya digunakan pada proses pengeringan ikan dan penghangat ruangan. Sedangkan pemanfaatan secara tak langsung ialah untuk pembangkit listrik[1].

Energi geothermal telah diidentifikasi sebagai sumber energi yang sustainable dan memproduksi emisi gas yang rendah[2]. Dengan besarnya potensial yang dimiliki oleh energi geothermal, Indonesia sedang merencanakan untuk meningkatkan produksi tenaga listrik dengan basis energi geothemal dari 1.196 menjadi 9.500 MW pada tahun 2025. Untuk mecapai target tersebut, sebuah kebijakan publik dibutuhkan untuk mendorong industri geothermal berkembang. Sekarang, total kapasitas PLTP di Indonesia sebesar 1.196 MW dari 7 PLTP di Indonesia[3].

Sistem panas bumi di Indonesia umumnya merupakan sistem hydrothermal yang mempunyai temperatur tinggi, yaitu $>225^{\circ} \mathrm{C}$, dan hanya beberapa di antaranya yang bertemperatur sedang, yaitu $150^{\circ} \mathrm{C}$ $-225^{\circ} \mathrm{C}[4]$. Karakteristik tersebut sangat berpotensi untuk dimanfaatkan menjadi energi listrik. Sistem hydrothermal yang ada di Indonesia didominasi oleh jenis dominasi air, dengan karakteristik fluida panas bumi sekitar 20\% uap dan $80 \%$ air. Jenis pembangkit listrik yang cocok digunakan untuk memanfaatkan potensi energi ini adalah pembangkit listrik tenaga panas bumi sistem flashing (single-flash). Pada sistem ini, fluida berfase cair (brine) hasil flashing langsung diinjeksikan kembali ke perut bumi (reservoir).

Di Indonesia, pembangkit listrik yang memanfaatkan sumber dominasi air hanya sampai ke tahap single-flash. Negara-negara lain telah mengembangkan pemanfaatan brine pada pembangkit listrik tenaga panas bumi dengan memflash ulang brine tersebut. Pembangkit dengan sistem ini dikenal sebagai pembangkit listrik tenaga panas bumi sistem double-flash. Uap yang dihasilkan dari proses flashing kedua digunakan untuk menggerakkan turbin pada pembangkit baru. Brine hasil single-flash masih memiliki temperatur yang cukup tinggi, sehingga dapat dimanfaatkan sebagai sumber panas untuk pembangkit listrik sistem double-flash. Oleh karena itu jenis sistem pembangkit listrik dengan memanfaatkan brine hasil flashing menjadi sangat layak untuk dikembangkan karena akan menghasilkan daya yang lebih besar dengan efisiensi yang lebih baik. Tujuan dari penelitian ini adalah untuk mengetahui tekanan flashing optimal pada pembangkit listrik tenaga panas bumi sistem double-flash.

\section{A. Pembangkit Listrik Tenaga Panas Bumi Sistem Single-Flash}

Pembangkit listrik sistem single-flash merupakan jenis pembangkit yang hanya mengalami satu kali proses flashing. Diagram alir pembangkit jenis ini ditunjukkan oleh Gambar 1. Fluida panas bumi, yang berasal dari dalam bumi, memasuki sumur produksi, titik 1 . Oleh karena terjadinya penurunan tekanan (pressure drop), fluida panas bumi mulai berubah fasa di titik 2, ketika memasuki separator. Brine dari separator, titik 3, diinjeksikan kembali ke perut bumi melalui sumur injeksi, sedangkan fasa uap (steam) hasil pemisahan separator, titik 4, dialirkan untuk mengekspansi turbin. Setelah keluar dari turbin, titik 5, steam tersebut dikondensasi di kondenser yang selanjutnya diinjeksikan kembali ke perut bumi, titik 6 . Proses termodinamika yang terjadi dari sumur produksi hingga sumur injeksi ditunjukkan pada diagram T$\mathrm{s}$, dengan temperatur pada siklus pembangkit diplot terhadap entropinya. Diagram tersebut ditunjukkan oleh Gambar 2. 


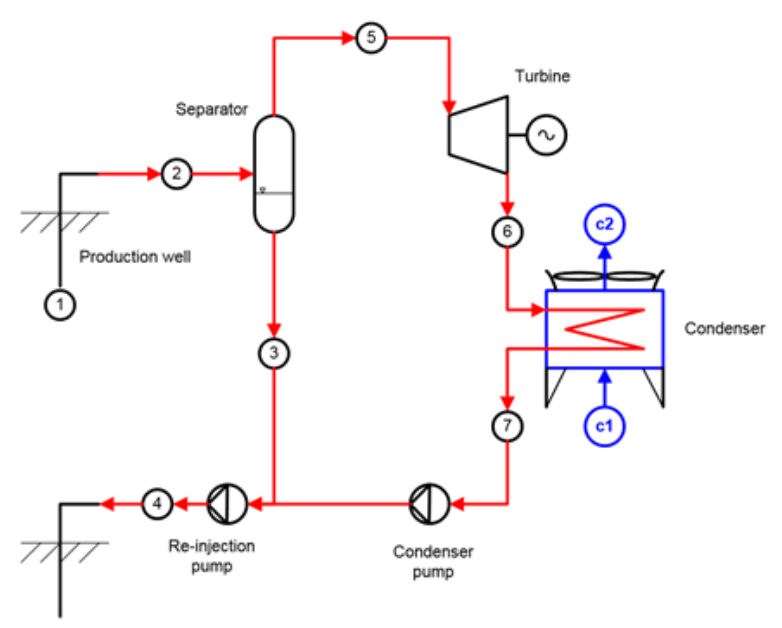

GAMBAR 1. Diagram alir pembangkit listrik tenaga panas bumi sistem single-flash[5].

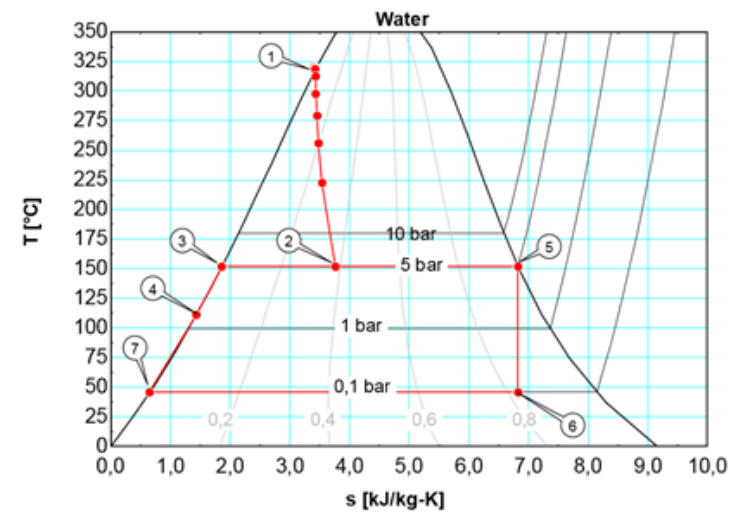

GAMBAR 2. Diagram T-s pembangkit listrik tenaga panas bumi sistem single-flash[5].

\section{B. Pembangkit Listrik Tenaga Panas Bumi Sistem Double-Flash}

Pembangkit listrik sistem double-flash merupakan pengembangan dari sistem singleflash yang dapat memproduksi sekitar 15-25\% daya yang lebih besar dengan kondisi fluida panas yang sama[6]. Pada prinsipnya, sistem ini sama dengan sistem single-flash, namun pada sistem double-flash, brine hasil flashing pertama diflash ulang menggunakan throttle valve sehingga diperoleh fasa uap yang digunakan untuk memutarkan turbin. Gambar 3. menunjukkan diagram alir pembangkit listrik tenaga panas bumi sistem double-flash. Fluida panas bumi dari reservoir memasuki sumur produksi, titik 1. Oleh karena terjadi pressure drop, fluida tersebut mengalami perubahan fasa, titik 2, ketika memasuki separator pertama. Brine yang keluar dari separator pertama, titik 3, diflash ulang menggunakan throttle valve sehingga diperoleh sebagian fasa uap (steam), titik 7. Biasanya, besarnya tekanan yang dihasilkan setelah proses flashing kedua mencapai sekitar 1-3 bar[7]. Digunakan separator kedua untuk memisahkan steam hasil flashing kedua. Steam hasil pemisahan tersebut, titik 8, dialirkan menuju turbin yang didesain sedemikian rupa, sehingga perbedaan tekanan pada stage pertama pada turbin sama dengan perbedaan tekanan antara separator pertama dengan separator kedua. Brine yang keluar dari separator kedua, titik 9, diinjeksikan kembali ke perut bumi bersamaan dengan fluida yang keluar dari kondenser, titik 6. Proses termodinamika yang terjadi pada pembangkit listrik sistem double-flash ditunjukkan pada diagram T-s, dengan temperatur pada siklus pembangkit diplot terhadap entropinya. Diagram tersebut ditunjukkan oleh Gambar 4. 


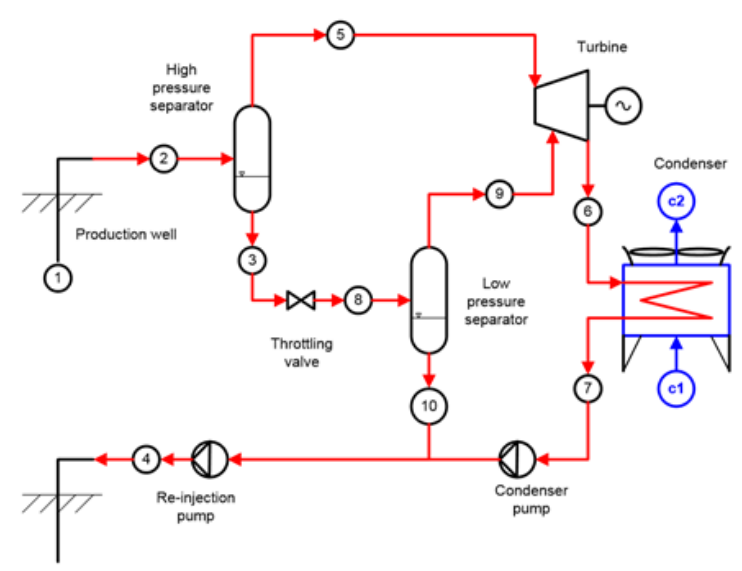

GAMBAR 3. Diagram alir pembangkit listrik tenaga panas bumi sistem double-flash.

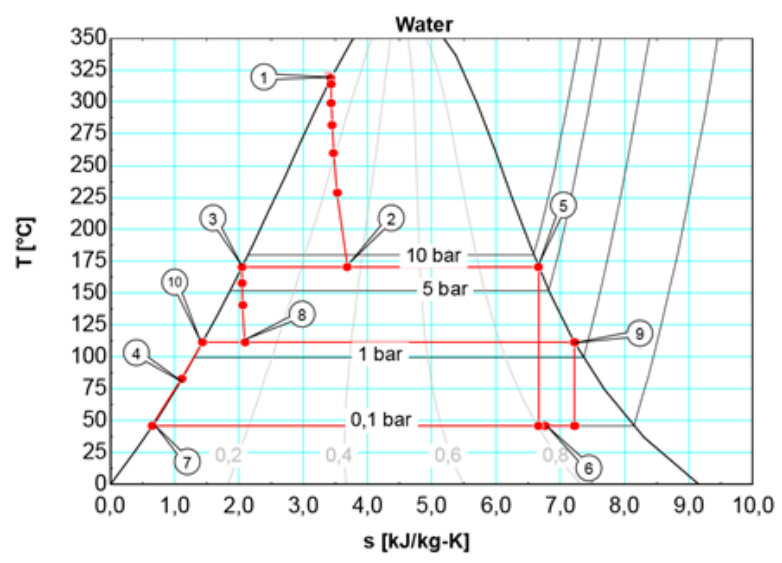

GAMBAR 4. Diagram T-s pembangkit listrik tenaga panas bumistem double-flash.

\section{Komponen-Komponen Pembangkit Listrik Tenaga Panas Bumi}

1. Flashing

Proses flashing merupakan proses perubahan fasa fluida dari fasa cair menjadi fasa uap dengan menurunkan tekanan fluida tersebut. Pada prosesnya, entalpi dari fluida yang memasuki valve (inlet) dan fluida yang keluar dari valve (outlet) adalah sama (isentropik).

$$
\mathrm{h}_{3}=\mathrm{h}_{8}
$$

dengan, $\mathrm{h}_{3}$ adalah entalpi di keadaan titik $3(\mathrm{~kJ} / \mathrm{kg})$ dan $\mathrm{h}_{8}$ adalah entalpi di keadaan titik $8(\mathrm{~kJ} / \mathrm{kg})$. Setelah itu dihitung fraksi uap yang akan dialirkan ke turbin menggunakan persamaan (2).

$$
X=\frac{h_{8}-h_{9}}{h_{10}-h_{9}}
$$

dengan, $X$ adalah fraksi uap hasil flashing, $\mathrm{h}_{10}$ adalah entalpi di keadaan titik 10 dalam fase gas $(\mathrm{kJ} / \mathrm{kg}), \mathrm{h}_{8}$ adalah entalpi di keadaan titik 8 dalam fase campuran, dan h $_{9}$ adalah entalpi di keadaan titik 9 dalam fase cair. 


\section{Turbin Uap}

Turbin uap merupakan komponen yang dapat mengubah entalpi uap menjadi kerja pada poros yang terkopel dengan generator listrik sehingga dapat menghasilkan energi listrik. Setelah diperoleh fraksi uap (kualitas uap) dari hasil flashing, dihitung daya Low Pressure Turbine menggunakan persamaan (3).

$$
\dot{W}_{L P}=\dot{m}\left(h_{10}-h_{11}\right)
$$

dengan, $\dot{W}_{L P}$ adalah daya low pressure turbine per satuan massa (Watt), $\dot{m}$ adalah laju alir massa fluida yang mengalir melalui turbin $(\mathrm{kg} / \mathrm{s}), h_{10}$ adalah entalpi pada keadaan $10(\mathrm{~kJ} / \mathrm{kg})$, dan $h_{11}$ adalah entalpi pada keadaan 11.

Setelah itu dilakukan perhitungan daya turbin high pressure menggunakan persamaan (4).

$$
\dot{W}_{H P}=\dot{m}\left(h_{4}-h_{5}\right)
$$

dengan, $\dot{W}_{H P}$ adalah daya turbin high pressure per satuan massa (Watt), $\dot{m}$ adalah laju alir massa fluida yang mengalir melalui turbin $(\mathrm{kg} / \mathrm{s}), h_{4}$ adalah entalpi pada keadaan $4(\mathrm{~kJ} / \mathrm{kg})$, dan $h_{5}$ adalah entalpi pada keadaan 5 .

Selanjutnya melakukan perhitungan efisiensi turbin dapat dihitung menggunakan persamaan (5) dan persamaan (6).

- high pressure turbine

- low pressure turbine

$$
\eta_{H P T}=\frac{h_{4}-h_{\underline{5}}}{h_{4}-h_{\underline{B S}}}
$$

$$
\eta_{L P T}=\frac{h_{10}-h_{11}}{h_{10}-h_{11 S}}
$$

dengan $\eta_{t}$ adalah efisiensi turbin, $h_{5 s}$ dan $h_{11 s}$ adalah nilai entalpi keluaran turbin di titik 5 dan titik 11 dengan keadaan isentropik.

\section{METODE PENELITIAN}

Metode yang digunakan dalam melakukan penelitian ini dimulai dengan studi literatur mengenai panas bumi (geothermal) secara umum dan pembangkit listrik tenaga panas bumi sistem flashing. Selanjutnya peneliti melakukan pembuatan model pembangkit listrik tenaga panas bumi sistem double-flash. Karakteristik fluida panas bumi yang digunakan pada penelitian ini ditunjukkan pada Tabel 1., yang merupakan data lapangan di salah satu pembangkit listrik panas bumi dominasi air di Jawa Barat.

TABEL 1. Karakteristik Fluida Panas Bumi yang Keluar dari Kepala Sumur

\begin{tabular}{cc}
\hline Parameter & Nilai \\
\hline Temperatur $\left({ }^{\circ} \mathrm{C}\right)$ & 180 \\
Tekanan $($ bar $)$ & 10 \\
Laju alir massa (ton/jam) & 2300 \\
Kualitas uap (\%) & 12,18 \\
\hline
\end{tabular}

Model pembangkit listrik sistem double-flash dibuat dengan menggunakan 2 turbin, yaitu High Pressure Turbine pada sistem flashing pertama dan Low Pressure Turbine pada sistem flashing kedua.

Variasi perubahan tekanan $(\Delta \mathrm{P})$ yang digunakan adalah 4 bar, 5 bar, 6 bar, 7 bar, 8 bar, dan 9 bar. Tekanan keluaran high pressure turbine dan low pressure turbine diasumsikan sebesar 0,8 bar. Proses flashing merupakan proses perubahan fasa fluida dari fasa cair menjadi fasa uap dengan menurunkan tekanan fluida tersebut. Fraksi uap (kualitas uap) hasil flashing dapat dihitung menggunakan persamaan 
(2). Setelah diperoleh fraksi uap dari hasil flashing, dihitung daya low pressure turbine menggunakan persamaan (3), daya high pressure turbine menggunakan persamaan (4), dan efisiensi turbin menggunakan persamaan (5) untuk high pressure turbine dan persamaan (6) untuk low pressure turbine.

Setelah itu peneliti membuat grafik hubungan antara daya terhadap perubahan tekanan $(\Delta P)$ dan kurva diagram T-s (temperatur terhadap entropi). Berikutnya dapat ditarik kesimpulan dari hasil penelitian ini.

\section{HASIL DAN PEMBAHASAN}

Skema pembangkit listrik tenaga panas bumi sistem double-flash yang telah dibuat ditunjukkan pada Gambar 5 serta diagram T-s ditunjukkan pada Gambar 6. Fluida panas bumi yang berasal dari dalam bumi memasuki sumur produksi, titik 1. Oleh karena terjadinya penurunan tekanan (pressure drop) ketika fluida mengalir dari reservoir menuju permukaan, fluida panas bumi mulai berubah fasa menjadi campuran air dan uap di titik 2. Fasa tersebut dipisahkan di separator. Fluida fasa uap (steam) hasil pemisahan separator, titik 4, dialirkan untuk mengekspansi High Pressure Turbine sehingga dihasilkan daya turbin sebesar 26,604 MW dengan efisiensi turbin sebesar $80,71 \%$. Setelah keluar dari turbin, titik 5, fluida tersebut dikondensasi di kondenser yang selanjutnya diinjeksikan kembali ke perut bumi. Brine yang keluar pada titik 3 diflash ulang menggunakan throttle valve sehingga diperoleh sebagian fasa uap (steam), titik 8 . Variasi perubahan tekanan yang digunakan pada proses ini sebesar 4 bar, 5 bar, 6 bar, 7 bar, 8 bar, dan 9 bar. Digunakan separator kedua untuk memisahkan steam hasil flashing kedua. Steam hasil pemisahan tersebut, titik 10, dialirkan menuju Low Pressure Turbine yang didesain sedemikian rupa. Brine yang keluar dari separator kedua, titik 9, diinjeksikan kembali ke perut bumi bersamaan dengan fluida yang keluar dari kondenser. Kualitas uap hasil flashing kedua, daya Low Pressure Turbine, dan efisiensi turbin yang dihasilkan ditunjukkan pada Tabel 2.

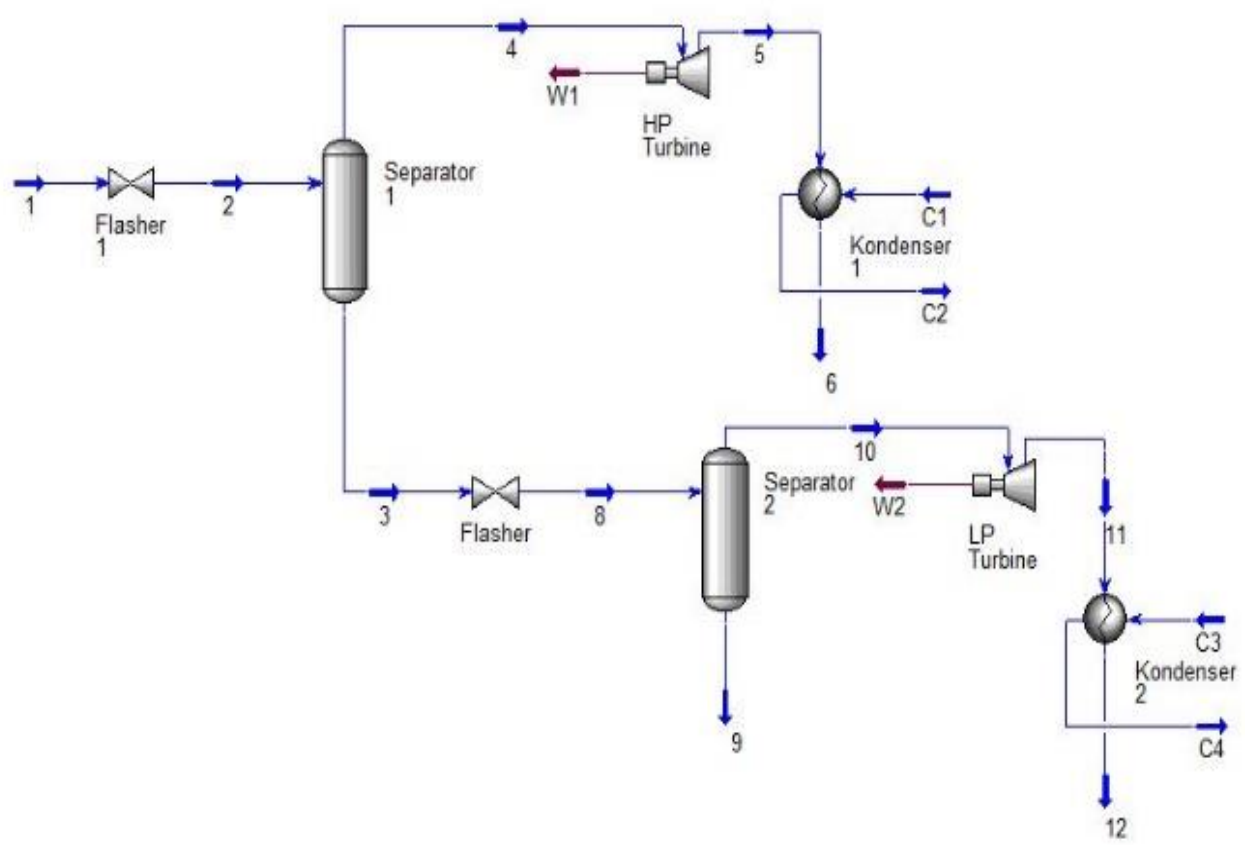

GAMBAR 5. Skema Pembangkit Listrik sistem double-flash 


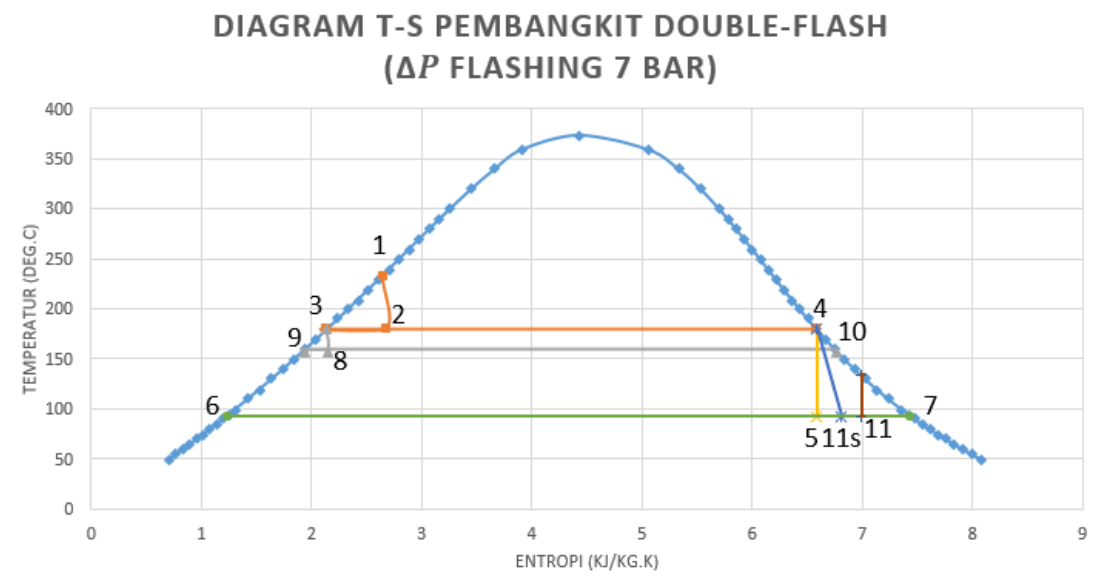

GAMBAR 6. Diagram T-s Pembangkit double-flash ( $\triangle \mathrm{P}$ flashing 7 bar)

Berdasarkan Tabel 2 dapat dilihat bahwa semakin besar $\Delta \mathrm{P}$ flashing, maka kualitas uap yang dihasilkan semakin besar, yaitu berkisar dari 0,0442 sampai 0,152. Besar laju alir massa yang digunakan untuk memutarkan turbin sebanding dengan besarnya kualitas uap yang dihasilkan pada proses flashing kedua. Hasil perhitungan menunjukkan bahwa daya yang dihasilkan pada Low Pressure Turbine cenderung meningkat seiring bertambah besarnya $\Delta \mathrm{P}$ flashing karena fasa uap yang dihasilkan semakin besar sehingga mass flow uapnya semakin banyak. Namun daya tersebut menurun ketika dilakukan flashing dengan $\Delta \mathrm{P}$ lebih besar dari 7 bar. Sementara nilai efisiensi turbin pada Low Pressure Turbine tidak mengalami penurunan, tetapi meningkat seiring dengan meningkatnya $\Delta \mathrm{P}$ flashing.

TABEL 2. Hasil Perhitungan Fraksi Uap, Daya Low Pressure Turbin dan Efisiensi Turbin pada Pembangkit Listrik sistem

\begin{tabular}{|c|c|c|c|c|c|c|}
\hline \multicolumn{7}{|c|}{ double-flash } \\
\hline$\triangle \mathrm{P}$ flashing (bar) & $\mathrm{x} 2$ & $\begin{array}{c}\mathrm{h} 11 \mathrm{~s} \\
(\mathrm{~kJ} / \mathrm{Kg})\end{array}$ & $\begin{array}{c}\mathrm{h} 11 \\
(\mathrm{~kJ} / \mathrm{Kg})\end{array}$ & $\begin{array}{c}\dot{\mathrm{m} g} 2 \\
\text { (Ton/jam) }\end{array}$ & $\begin{array}{c}\dot{\mathrm{w} t} 2 \\
(\mathrm{MW})\end{array}$ & $\begin{array}{c}\mathrm{nt} \\
(\%)\end{array}$ \\
\hline 4 & 0.0442 & 2418.426 & 2480.876 & 89.308 & 6.845 & 81.544 \\
\hline 5 & 0.0581 & 2440.868 & 2496.767 & 117.42 & 8.217 & 81.841 \\
\hline 6 & 0.074 & 2468.260 & 2516.361 & 149.614 & 9.236 & 82.207 \\
\hline 7 & 0.093 & 2503.463 & 2541.876 & 187.93 & 9.5752 & 82.684 \\
\hline 8 & 0.1172 & 2553.04 & 2578.594 & 236.743 & 8.424 & 83.37 \\
\hline 9 & 0.1529 & 2638.224 & 2643.967 & 308.899 & 2.705 & 84.591 \\
\hline
\end{tabular}

Gambar 7 merupakan grafik yang menunjukkan pengaruh perubahan tekanan pada proses flashing dengan daya turbin yang dihasilkan. Dapat diketahui bahwa nilai tekanan optimal pada proses flashing kedua terjadi ketika dilakukan flashing dengan perubahan tekanan ( $\Delta \mathrm{P}$ flashing) sebesar 7 bar. Tekanan masuk turbin pada keadaan ini adalah 3 bar, dan daya yang dihasilkan adalah 9,5752MW. Bila $\Delta \mathrm{P}$ flashing diperbesar, $\Delta \mathrm{P}$ flashing lebih besar dari 7 bar, daya yang dihasilkan akan semakin menurun, yaitu $8,4245 \mathrm{MW}$ pada $\Delta \mathrm{P}$ flashing 8 bar (tekanan masuk turbin 2 bar), dan 2,7056MW pada $\Delta \mathrm{P}$ flashing 9 bar (tekanan masuk turbin 1 bar). 


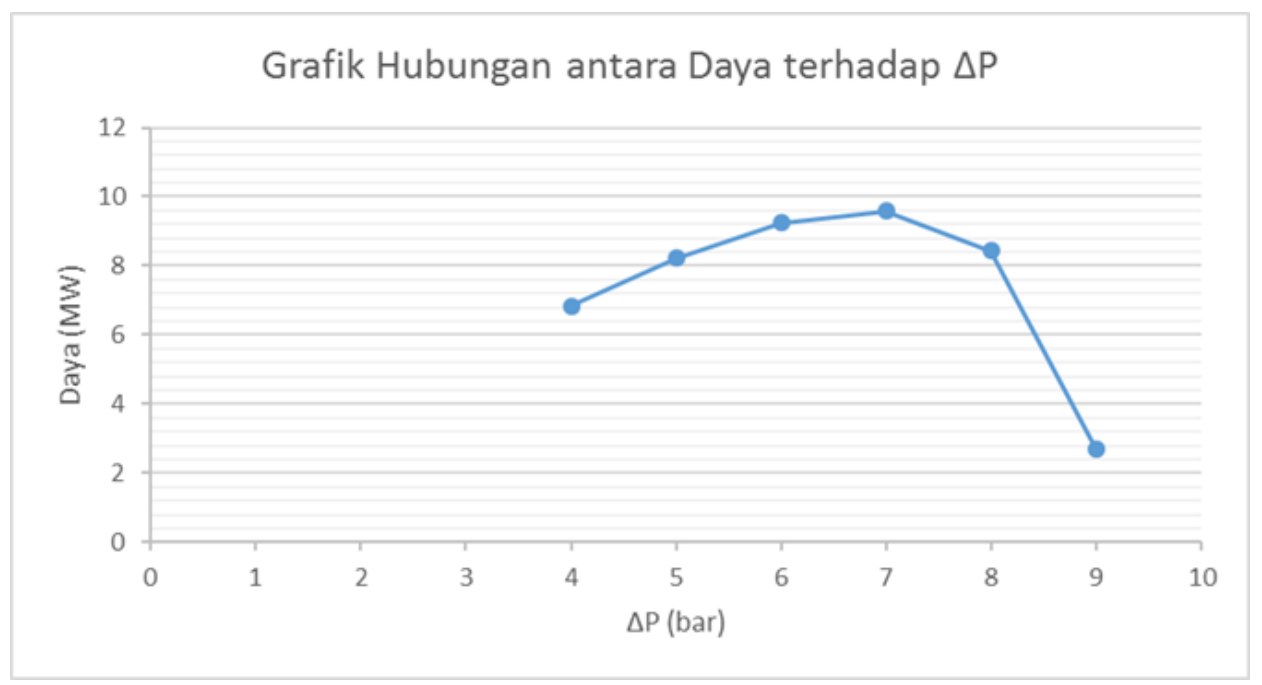

GAMBAR 7. Grafik Hubungan antara Daya terhadap Perubahan Tekanan

Berdasarkan grafik yang ditunjukkan pada Gambar 7. dapat diketahui bahwa tekanan optimal untuk tekanan masuk pada Low Pressure Turbine adalah 3 bar, dan bila lebih rendah dari itu maka energi yang dimiliki fluida panas bumi tersebut akan semakin menurun sehingga daya turbin yang dihasilkan akan semakin kecil.

Penurunan nilai daya turbin ini dapat dilihat dari nilai entalpi di keadaan 11 (keluaran turbin). Pada keadaan $\Delta \mathrm{P}$ flashing di atas 7 bar, nilai entalpi di keadaan 11 akan meningkat jauh lebih besar dibandingkan dengan pada $\Delta \mathrm{P}$ flashing kurang dari 7 bar. Nilai daya turbin ditentukan oleh selisih nilai entalpi masuk dan nilai entalpi keluaran turbin, sehingga bila nilai entalpi keluaran turbin meningkat jauh lebih besar maka daya turbin yang dihasilkan akan lebih kecil.

\section{SIMPULAN}

Berdasarkan hasil penelitian telah diperoleh nilai tekanan optimal pada model pembangkit listrik tenaga panas bumi sistem double-flash yang memiliki temperatur dan tekanan di kepala sumur $180^{\circ} \mathrm{C}$ dan 10bar, yaitu $\Delta \mathrm{P}$ flashing sebesar 7 bar (tekanan masuk turbin 3 bar). Daya pada Low Pressure Turbin yang dihasilkan pada keadaan ini adalah 9,575 MW dengan efisiensi turbin 82,68\%. Bila $\Delta \mathrm{P}$ flashing lebih besar dari 7 bar (tekanan masuk turbin lebih kecil dari 3 bar) daya yang dihasilkan akan semakin menurun karena energi yang dimiliki fluida panas bumi pada keadaan ini semakin menurun.

\section{UCAPAN TERIMAKASIH}

Ucapan terima kasih kami sampaikan kepada Prodi Fisika Universitas Padjadjaran yang telah memfasilitasi kami dalam melakukan penelitian ini.

\section{REFERENSI}

[1] Direktorat Jenderal Kelembagaan IPTEK \& DIKTI. 2014. Undang-Undang Republik Indonesia Nomor 21 Tahun 2014 Tentang Panas Bumi [Online]. Available: http://kelembagaan.ristekdikti.go.id

[2] Mathew Aneke et al., "Performance Analysis of The Chena Binary geothermal Power Plant", Appl Therm Eng, 2011, 31 : 1825-32, doi: 10.1016/j.applthermaleng.2011.02.028

[3] Halldór Ármannsson et al., "CO2 emissions from geothermal power plants and natural geothermal activity in Iceland", Geothermics, 2005, 34 : 286-96, doi: 10.1016/j.geothermics.2004.11.005 
[4] DiPippo, R., 2008: Geothermal power plants: Principles, applications, case studies and environmental impact (2nd edition). Butterworth-Heinemann (Elsevier), Oxford, $520 \mathrm{pp}$.

[5] Dr. Páll Valdimarsson, Geothermal power plant cycles and main components, UNU-GTP and LaGeo, in Santa Tecla, El Salvador, January 16-22, 2011.

[6] Karlsdottir et al., Comparison of Methods for Utilization of Geothermal Brine for Power Production, World Geothermal Congress 2010, Bali, Indonesia.

[7] Gudmundur Kjartansson, Low Pressure Flash-Steam Cycle at Hellisheidi-Selection Based on Comparison Study of Power Cycles, Utilizing Geothermal Brine, Proceedings World Geothermal Congress 2010, Bali, Indonesia, 25-29 April 2010. 
